\title{
Variations of Musculocutaneous Nerve Combined with High Bifurcation of the Brachial Artery
}

\author{
Xiaoli Chen, Chengkai Fu, Chunxu Guo, Jian Wang, Ze Jiang, Lina Leng, Daowen Si* \\ College of Basic Medical Sciences, North China University of Science and Technology, Tangshan, China \\ Email:3304600593@qq.com, * sidaowen@126.com
}

How to cite this paper: Chen, X.L., Fu, C.K., Guo, C.X., Wang, J., Jiang, Z., Leng, L.N. and Si, D.W. (2018) Variations of Musculocutaneous Nerve Combined with High Bifurcation of the Brachial Artery. Open Access Library Journal, 5: e4791. https://doi.org/10.4236/oalib.1104791

Received: July 25, 2018

Accepted: August 7, 2018

Published: August 10, 2018

Copyright $\odot 2018$ by authors and Open Access Library Inc.

This work is licensed under the Creative Commons Attribution International License (CC BY 4.0).

http://creativecommons.org/licenses/by/4.0/

\begin{abstract}
During a routine dissection of the right upper limb of a 65-year-old male cadaver whose death is not clear, we found two anatomical abnormalities on the musculocutaneous nerve and brachial artery on the same arm. First, the musculocutaneous nerve derived from the lateral fascicles of brachial plexus by two branches. Second, the brachial artery emitted the radial and ulnar arteries at the level of $1 / 3$ proximal upper arm. Given these variations are discovered rarely and accurate knowledge of such variations is important for both surgeons and radiologists.
\end{abstract}

\section{Subject Areas}

Neurology

\section{Keywords}

Variations, Musculocutaneous Nerve, High Bifurcation, Brachial Artery

\section{Introduction}

Single anatomical variation in the upper limb is common [1]. The brachial plexus is the most variable part of the peripheral nervous system [2]. As one of the terminal branches of the brachial plexus, the variations of musculocutaneous nerve have been discussed by many previous documents. Several variations about the musculocutaneous nerve are on the basis of its origin, relations to the muscles of the arm, relations to the median nerve and its distributions [3]. Our case shows the musculocutaneous nerve deriving from the lateral fascicles by two branches, meanwhile associating with the high bifurcation of the brachial 
artery on the same arm. This case is rare to find. Awareness of these variations is very vital in clinic.

\section{Case Report}

During our routine dissection, we observed two anatomical variations on the right upper of an adult male cadaver. A detailed description of each variation follows.

First one: the musculocutaneous nerve derived from lateral fascicles of brachial plexus by two branches. The proximal tiny first branch dominated the coracobrachialis. The distal second one was the main trunk of the musculocutaneous nerve, and then continued to emit two muscular branches to innervate bicepsbrachii and brachialis, the terminal branch transits to the lateral antebrachial cutaneous nerve. The transverse diameter of the lateral cord of the brachial plexus was $4.49 \mathrm{~mm}$, its root emitted the tiny first branch $(0.96 \mathrm{~mm}$ in diameter), after going down $3.25 \mathrm{~cm}$ in distance, it reached the coracobrachialis. The lateral and medial cords which formed the right median nerve descended in a longer distance than usual and converged into the median nerve $(4.60 \mathrm{~mm}$ in diameter). No abnormalities were found in the median nerve. The second branch of the musculocutaneous nerve came from the lateral fascicles and was $5.79 \mathrm{~cm}$ distal to the lower segment of the pectoralis minor muscle, the initial diameter of this branch was $3.20 \mathrm{~mm}$. The second branch which transverse diameter was $1.58 \mathrm{~mm}$ sent out the muscular branch to the bicepsbrachii after descending laterally $2.04 \mathrm{~cm}$, and then went down $4.81 \mathrm{~cm}$ to the deep surface of the bicepsbrachii. The main trunk of the second branch $(2.14 \mathrm{~mm}$ in diameter) continued downward, it issued muscular branch of the brachial muscle $(1.30 \mathrm{~mm}$ in diameter) at a distance of $7.69 \mathrm{~cm}$ and then descended $2.67 \mathrm{~cm}$ to the parochial muscle. The main trunk continued as the lateral cutaneous nerve of forearm and the transverse diameter was $2.04 \mathrm{~mm}$ (Figure 1 \& Figure 2).

Second one: the brachial artery emitted the radial and ulnar arteries at the level of $1 / 3$ proximal upper arm. The transverse diameter of the parochial artery at the beginning of the inspectorate major muscle was $4.83 \mathrm{~mm}$, and the radial artery and the ulnar artery were emitted after $2.25 \mathrm{~cm}$ descending with diameters $3.74 \mathrm{~mm}$ and $4.35 \mathrm{~mm}$ respectively. The radial artery went into the medial part of the median nerve, and it moved to the radial side gradually after arriving at the cubitalfossa. The ulnar artery travelled through the lateral part of the median nerve and arrived at the cubital fossa in the arm. The rest of the lines were normal (Figure 1 \& Figure 2).

\section{Discussion}

According to anatomical knowledge, under normal circumstances, the musculocutaneous nerve as one of the terminal branches of the brachial plexus originates from the fascicles lateral plexus brachialis, pierces the coracobrachialis muscle, and descends between the biceps brachii and the brachialis muscle. It 


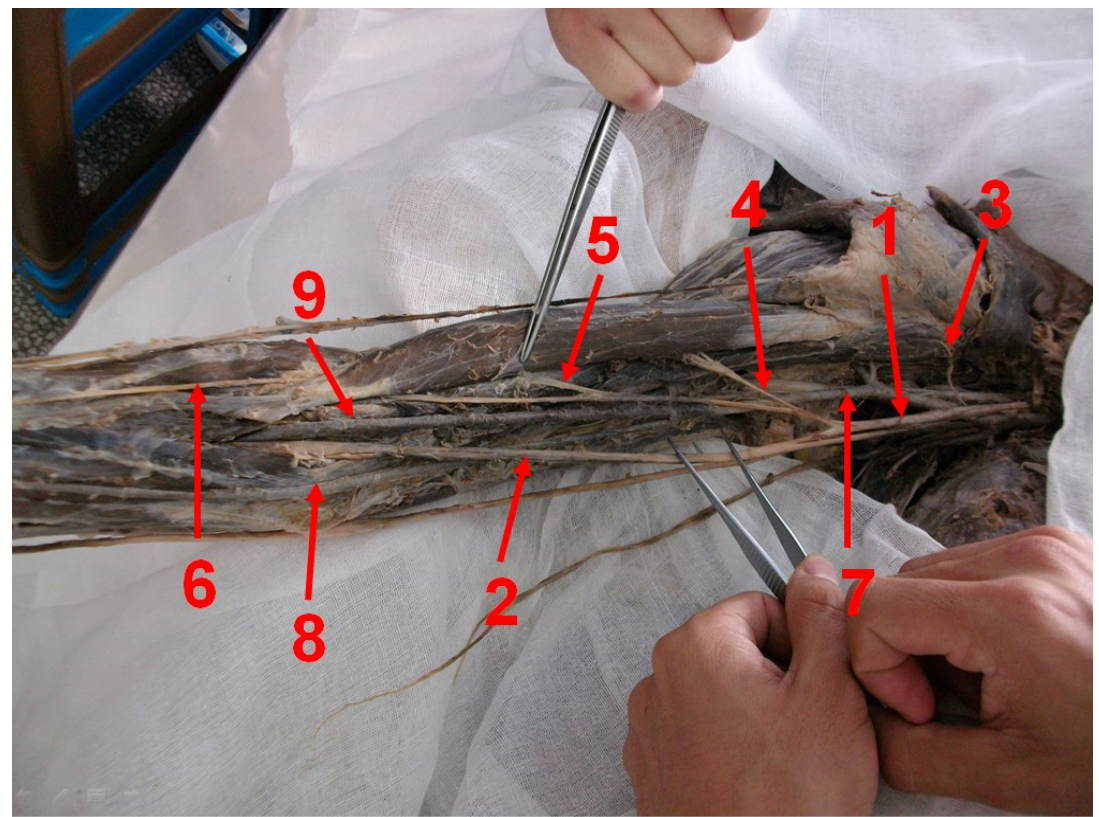

Figure 1. Variations of musculocutaneous nerve. 1: Lateral fasciculus of brachial plexus; 2: Median nerve; 3: Muscular branch of the coracobrachialis muscle; 4: Muscular branch of the bicepsbrachii; 5: Muscularbranch of the brachialis; 6: Lateral antebrachial cutaneous nerve; 7: Brachial artery; 8: Radial artery; 9: Ulnar artery.

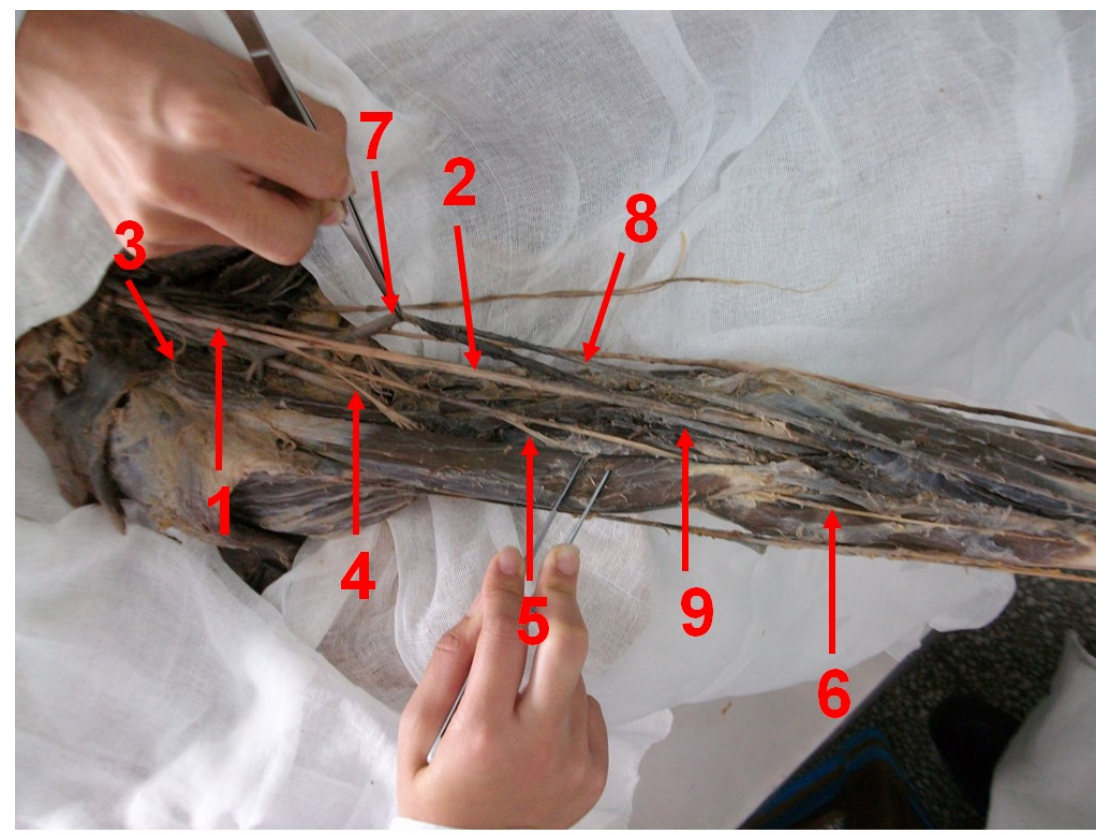

Figure 2. The high bifurcation of the brachial artery. 1: Lateral fasciculus of brachial plexus; 2: Median nerve; 3: Muscular branch of the coracobrachial muscle; 4: Muscular branch of the bicepsbrachii; 5: Muscular branch of the brachialis; 6: Lateral antebrachial cutaneous nerve; 7: Brachial artery; 8: Radial artery; 9: Ulnar artery.

issues Rami muscularis to the three muscles along the way, and the terminal branch extends as the lateral antebrachial cutaneous nerve. Variations of the brachial plexus and its terminal branches are not uncommon [4]. Taking into all 
cases into account, the most frequently found variations include the presence of communicating branches with the median nerve, the nerve not piercing the coracobrachialis muscle and its absence [5]. In presented case, however, lateral fascicles descend in a longer distance than usual and the musculocutaneous nerve derived from the lateral fascicles by two branches. It does not fit in any type of the previous classification by Pilar [5].

Generally, the brachial artery goes down along the medial bicipital groove with accompanying of the median nerve and terminates by dividing into the radial and ulnar arteries at the level of the neck of the radius. In our specimen, the radial and ulnar arteries were sent out at the level of $1 / 3$ proximal upper arm, belonging to the high bifurcation of the brachial artery. Knowing that such artery variation is necessary to arterial cannula, inappropriate cannula can result in thrombosis, gangrene, and even limb loss [6]. Although high brachial artery bifurcation is not a rare occurrence [7], high bifurcation of the brachialartery coexisting with the multiple branches of the musculocutaneous nerve is rare to see.

Literatures on the variation of the musculocutaneous nerve and the high bifurcation of the brachial artery have been reported by various authors, but, to our knowledge, multiple branches of the musculocutaneous nerve together with high bifurcation of the brachial artery at the same arm have never been reported in previous documents. From a clinical point of view, awareness of variations in the upper extremity is essential to prevent unnecessary injury during the surgery, especially in orthopaedics trauma cases [8].

\section{Acknowledgements}

This study was supported by North China University of Science and Technology.

\section{Conflicts of Interest}

The authors declare no conflicts of interest regarding the publication of this paper.

\section{References}

[1] Lee, S.H., Jeon, J.Y. and Yoon, S.P. (2014) A Combined Variation of the Musculocutaneous Nerve Associated with a Supernumerary Head of the Biceps Brachii Muscle. Folia Morphologica ( Warsz), 73, 366-369.

[2] Johnson, E.O., Vekris, M., Demesticha, T. and Soucacos, P.N. (2010) Neuroanatomy of the Brachial Plexus: Normal and Variant Anatomy of Its Formation. Surgical and Radiologic Anatomy, 32, No. 3. https://doi.org/10.1007/s00276-010-0646-0

[3] Ebrahimzadeh-Bideskan, A., Ebrahimzadeh, M.H., Mohammadipour, A. and Khordad, E. (2013) A Rare Anatomical Variation of the Brachial Plexus Characterized by the Absence of the Musculocutaneous Nerve. Zahedan Journal of Research in Medical Sciences, 15, 74-77.

[4] Radunovic, M., Vukasanovic-Bozaric, A., Radojevic, N. and Vukadinovic, T. (2013) A New Anatomical Variation of the Musculocutaneous and the Median Nerve 
Anastomosis. Folia Morphologica ( Warsz), 72, 176-179.

[5] Guerri-Guttenberg, R.A. and Ingolotti, M. (2009) Classifying Musculocutaneous Nerve Variations. Acta Anaesthesiologica Scandinavica, 22, 671-683.

[6] Cherukupalli, C., Dwivedi, A. and Dayal, R. (2008) High Bifurcation of Brachial Artery with Acute Arterial Insufficiency: A Case Report. Vascular and Endovascular Surgery, 41, 572-574.

[7] Kian, K., Shapiro, J.A., Salman, L., Khan, R.A.H., Merrill, D., Garcia, L., Eid, N., Asif, A., Aldahan, A. and Beathard, G. (2012) High Brachial Artery Bifurcation: Clinical Considerations and Practical Implications for an Arteriovenous Access. Seminars in Dialysis, 25, 244-247.

[8] Troupis, T., Michalinos, A., Protogerou, V., Mazarakis, A. and Skandalakis, P. (2015) Complex Anatomic Variation in the Brachial Region. Folia Morphologica (Warsz), 74, 118-121. 